\title{
Traduzindo o erotismo místico do conto "Eucaristia", de Andréa del Fuego
}

Rosvitha Friesen Blume

A tradução do conto "Eucaristia" deu-se no contexto de um trabalho conjunto entre mim como professora orientadora e três alunas da Universidade de Leipzig após um curso de tradução literária que ofereci naquela instituição em 2006. Na ocasião propusemos um projeto de tradução e publicação de uma antologia de contos de escritoras brasileiras contemporâneas na Alemanha. ${ }^{1}$

Após o assim denominado cultural turn nos Estudos da Tradução, é lugar comum que a tradução excede em muito uma operação de ordem linguística. Nas palavras de Bassnett/Lefevere, "neither the word, nor the text, but the culture becomes the operational 'unit' of translation." 2 Para David Katan o tradutor figura como mediador, sendo a natureza dessa tarefa a seguinte: "translation for a mediator is not only about language or texts; it is a way to improve understanding between mutually non-comprehending groups." ${ }^{3} \mathrm{O}$ processo tradutório

O projeto está concluído e estamos negociando a publicação da antologia com uma editora alemã.

2 Bassnett, Susan/ Lefevere, André (Eds.). Translation, History and Culture. London and New York: Pinter Publishers, 1990, p. 8.

3 Katan, David. "What is it that's going on here?": Mediating Cultural Frames in Translation. In: Bassnet, S./ Bosinelli, R.M.B./ Olrych, M. (ed.). Translation Studies Revisited. Textus (English Studies in Italy) Vol. XII 1999, n. 2, p. 420. 
Rosvitha Friesen Blume. Traduzindo o erotismo místico do conto "Eucaristia",...

constitui-se, pois, muito mais numa mediação entre culturas do que numa transposição linguística.

Porém, esse trabalho de mediação na prática nem sempre é fácil para tradutores/as, já que frequentemente eles/as têm conhecimentos razoáveis de estruturas linguísticas numa determinada língua estrangeira, mas carecem de uma vivência cultural mais ampla na cultura da língua de partida dos textos a serem traduzidos. Por outro lado, tradutores/as que têm conhecimento amplo de uma determinada cultura por viverem nela e que gostariam de traduzir textos para uma língua estrangeira que dominam encontram dificuldades no processo tradutório por lhes faltar a vivência imediata na língua/cultura do texto de chegada, em termos de suas estruturas e vocabulário atualizado e específico.

O presente artigo comenta o referido projeto de tradução, que proporcionou uma experiência de mediação cultural muito interessante ao unir a minha vivência cultural enquanto nativa da língua de partida e a vivência linguístico-cultural de falantes nativas da língua de chegada.

A experiência foi muito enriquecedora para ambos os lados, pelo fato de os contos por mim selecionados e traduzidos pelas alunas haverem sido amplamente discutidos em termos de sua interpretação e de suas opções tradutórias; em um intenso contato via email pude oferecer ajuda especialmente na identificação do contexto cultural estranho às tradutoras e, por outro lado, elas retextualizaram os contos em alemão atual e adequado, de modo a permitir a aproximação do leitor alemão a esse contexto cultural estranho.

Gostaria de apontar aqui algumas questões tradutórias discutidas no conto traduzido pela aluna Claudia Hahn, "Eucaristia", de Andréa del Fuego, que encontraram exatamente nesse processo de mediação cultural soluções, a meu ver, bem sucedidas.

A contista, na verdade Andréa Fátima dos Santos, escolheu o seu 'pseudônimo' em homenagem a Luz del Fuego, a famosa dançarina brasileira dos anos 50. Del Fuego, a jovem escritora nascida 
em 1975, vem de São Paulo. É autora de três livros de contos, Minto enquanto posso (2004), Nego tudo (2005) e Engano seu (2007), além de várias participações em antologias. O erotismo é uma temática central em sua obra.

No conto "Eucaristia", a protagonista, uma quarentona de classe média-baixa, mulher de motorista de ônibus, é devota fanática de São Jorge. Ajoelha-se diariamente diante de um altar em sua casa, passando horas junto a ele, chegando mesmo a entrar em transe, o que deixa a família preocupada. À noite tem sonhos eróticos com o santo, o que lhe causa remorsos. Certa noite, como na lenda, São Jorge chega a cavalo e a salva das garras ameaçadoras de um dragão; em seguida rende-se a ela numa união místico-erótica.

O maior desafio para a tradutora alemã não foram questões linguísticas de vocabulário ou de sintaxe e nem mesmo o estilo paratáctico do conto e a descontinuidade em sua estrutura temporal; a dificuldade residia no entendimento do contexto cultural em que ele está inserido, qual seja o de um erotismo que nasce a partir da vivência de uma intensa religiosidade, que por sua vez se caracteriza pelo seu sincretismo, com o predomínio da religião oficial, o catolicismo, aliado à expressão religiosa de origem africana e a outras correntes espiritualistas. Tudo isso se configura muito estranho à cultura alemã. Esta é, de modo geral, mais secularizada que a brasileira, especialmente no leste, onde também fica Leipzig, devido aos mais de quarenta anos de comunismo, além de outros fatores que não cabe mencionar nos limites deste texto; a religião católica se concentra tão somente no sul da Alemanha, e mesmo lá não exerce tão forte influência como no Brasil.

O desafio no processo tradutório foi, portanto, procurar reconstruir o texto para o público leitor alemão sem apagar este contexto cultural brasileiro, já que é exatamente a partir dele que se constrói o erotismo no conto.

$\mathrm{Na}$ cultura ocidental, a relação entre religiosidade e erotismo nasce a partir da separação rigorosa entre corpo e espírito pregada pelo catolicismo, que valoriza o último em detrimento do primeiro, 
Rosvitha Friesen Blume. Traduzindo o erotismo místico do conto "Eucaristia",...

o lugar do pecado. O desejo sexual é visto como o desejo da carne, que é condenável e, portanto, proibido. E é aí que floresce o erótico. Segundo Bataille, "o desejo do erotismo é o desejo que triunfa do interdito". ${ }^{4}$

Porém, parece que os elementos da religiosidade do conto em questão transcendem esse nível de função proibitiva que aguçaria os sentidos. Voltando a Bataille, este compara o erotismo também, de certa maneira, à própria experiência mística, se não em sua natureza, ao menos em sua força arrebatadora: "por enquanto, contentome com olhar a emoção da santidade de um lado e a emoção do erótico de outro, enquanto objetos de extrema intensidade." ${ }^{5}$ Interpretando essa ideia de Bataille, Valença diz que "o erótico e o místico tocam-se porque constituem experiências que rompem com o mundo ordenado em que impera a descontinuidade. Constituem estados emocionais que permitem a passagem do descontínuo ao contínuo e, enquanto tal, inserem-se contra a angústia inerente à existência, ao estar no mundo." ${ }^{6}$ É o que se realiza no conto: a personagem, insatisfeita com a vida, encontra no âmbito da experiência místico-erótica a sua realização. E a construção deste enredo encontra no contexto cultural brasileiro, fortemente embebido de religiosidade e misticismo, o espaço perfeito para a sua realização.

O erotismo no texto de Andréa del Fuego é construído então, de modo sutil, a partir dos elementos de religiosidade empregados, que frequentemente têm duplo sentido e servem como alusões ao erótico.

O título conduz o leitor ao imaginário religioso. Mas então o conto inicia com a narração dos desejos da protagonista, e, logo a seguir, fala de sua devoção a São Jorge, sabidamente o santo guer-

Bataille, Georges. O erotismo. Trad. De Antônio Carlos Viana, 2. ed., Porto Alegre: L\&PM, 1987, p. 238.

5 Bataille op. cit., p. 235.

6 Valença, Ana Maria Macedo. Um olhar sobre o erotismo. In: Revista Brasileira de Sexualidade Humana. Vol. 5, n. 2, 1994, p. 158. (disponível em: www.adolec.br/bus/adolec/P/ pdf/volumes/volume5_2.pdf ) 
reiro montado num cavalo branco e de espada em punho. Considerando uma personagem feminina cheia de desejos, o que vem à mente do leitor brasileiro a respeito da imagem deste São Jorge é sua acentuada virilidade, muito embora seja um "santo"7 adorado pela fiel. A frase "Não há manifestação em que acredite mais, em que confie tanta profundeza e pele" já sinaliza a natureza da experiência vivida pela protagonista ao final do conto, o êxtase de uma experiência místico-erótica. O elemento formal da aliteração só reforça a ideia.

Depois há no texto a referência aos orixás, além das "grossas e brilhantes colunas de cera" do altar que lembram o candomblé. As "tensões" das "quarentonas" são dissolvidas "conversando sobre violência, orixás e homens". Mais uma vez se aproxima a fé com a corporalidade humana. Vale lembrar que no candomblé não há a noção de pecado aliada aos prazeres do corpo.

Na procissão de São Jorge, Bárbara "caminha como sangue nas veias daquele que entrega a própria espada", frase esta de duplo sentido. A seguir há uma referência a um ritual católico, "Bárbara bate os joelhos em frente ao altar todos os dias", sendo que "o cavaleiro de gesso repousa num tecido urdido por suas mãos". Mais uma vez o que se destaca é o aspecto físico, o toque entre a personagem e o santo. E logo em seguida vem a declaração "a fé é seu pilar central”, mais uma imagem fálica, além das grossas velas de cera e da espada.

Ela "não teme a morte do corpo, mas as necessárias para se encaixar na órbita dos elétrons, no eterno". O vocabulário é da filosofia espiritualista do Racionalismo Cristão, de origem brasileira, permitindo, igualmente, outras leituras nesse contexto.

"Sua respiração se ordenou em palavras cantadas. Pontos cantados. Orava hipnótica melodia", lembra o discurso da filosofia da Nova Era, discurso esse que serve aqui como metáfora para o crescimento do êxtase sexual.

A personagem está alheia ao fato que São Jorge não é oficialmente reconhecido como santo pela igreja católica por falta de fontes históricas seguras que atestem sua existência. 
Rosvitha Friesen Blume. Traduzindo o erotismo místico do conto "Eucaristia",...

"Estava embriagado pelo fermento das uvas de Salomão" é uma alusão bíblica, do livro de Cantares de Salomão, uma poesia de forte conotação erótica. É nesse ponto que se dá a conexão do conto com o seu título, no vinho da eucaristia, ou da comunhão, que se torna plena ao final, quando, então, "acenderam a fornalha para a mistura das divinas substâncias". A linguagem desta última frase remete ao misticismo da cabala judaica, ao mesmo tempo em que nesse contexto representa o clímax da experiência sexual.

$\mathrm{Na}$ tradução, a primeira tendência foi no sentido do apagamento de certos elementos específicos dessa cultura, dado o desconhecimento da mesma pela tradutora. E aí se iniciou nosso processo de mediação. De um lado veio o subsídio interpretativo de minha parte, enquanto conhecedora da cultura brasileira, e de outro, a oferta de soluções linguísticas em alemão pela tradutora, que permitissem ao público-alvo uma aproximação a esse universo cultural estranho para ele. Consideramos necessária uma explicitação maior de algumas expressões que no português eram sutis, a fim de possibilitar ao público leitor alemão a compreensão dessa conjunção entre o místico e o erótico.

Em primeiro lugar, dificilmente se poderá presumir o conhecimento da lenda de São Jorge na Alemanha. E, como se trata de um elemento fundamental para a compreensão do conto, a tradutora optou por um paratexto em forma de nota de rodapé.

O conto inicia com as frases "Bárbara ama seu esposo. Mas deseja muito mais." O verbo da segunda frase pode ser entendido numa primeira leitura como 'querer', 'almejar', wollen em alemão. Porém, a tradutora optou por aber sie begehrt viel mehr. O verbo begehren significa 'ter um desejo forte', frequentemente em conotação sexual.

A frase "não há manifestação em que acredite mais, em que confie tanta profundeza e pele" foi traduzida por es gibt nichts anderes, an das sie stärker glaubt, dem sie so mit Haut und Haaren verfallen ist. A última parte da frase, mit Haut und Haaren verfallen, é uma expressão fixa em alemão, que denota uma paixão arrebatadora, no sentido 
erótico-amoroso, bem menos sutil que a frase em português (mit Haut und Haaren significa 'com pele e cabelos'; verfallen neste caso seria 'sexualmente dependente'). Dessa maneira possibilita-se ao público leitor alemão a conexão entre a devoção ao santo e a paixão física por ele, além de se reconstruir o elemento formal da aliteração.

Para manter a referência aos orixás da cultura afro-brasileira, a tradutora optou por "deuses afro": über Gewalt, Afro-Gottheiten und Männer.

Na frase que alude à filosofia do Racionalismo Cristão, "não teme a morte do corpo, mas as necessárias para se encaixar na órbita dos elétrons, no eterno", fizemos questão de uma tradução muito próxima ao texto de partida, embora o plural de morte no alemão seja raro; desta forma a estrutura causa uma estranheza na língua de chegada e chama a atenção para a natureza mística do enunciado.

A frase "deslizando, saiu do templo para fazer as curvas do jardim" remete, evidentemente, às curvas do corpo, conotando o prazer da personagem. Como uma tradução literal para o alemão de "para fazer as curvas do jardim" não seria possível, segundo a tradutora, ela encontrou a solução um im Garten lustzuwandeln, com o intuito de manter a conotação erótica, mesmo que em outra estrutura. O verbo lustwandeln significa passear vagarosa e confortavelmente num parque ou lugar semelhante, sem alusão alguma a erotismo, mas como se trata de um vocábulo arcaico e, portanto, quase desconhecido hoje, o que provavelmente mais chamará a atenção é sua primeira parte, que vem do substantivo Lust, e que significa desejo, gozo. Mais uma vez há, portanto, uma explicitação do erotismo.

Mesmo não tendo como identificar especificamente a origem de todas as expressões de ordem mística ou religiosa do texto, acreditamos que a tradução aqui apresentada permite ao leitor uma aproximação ao universo cultural em que se situa esse conto, o de um intenso sincretismo religioso e de um erotismo que floresce exatamente a partir dele. 
Rosvitha Friesen Blume. Traduzindo o erotismo místico do conto "Eucaristia",...

E o processo de tradução/mediação, por sua vez, configurouse numa frutífera troca de vivências linguístico-culturais para as participantes do projeto.

\section{Eucaristia $^{8}$}

\section{Andréa del Fuego}

Bárbara ama seu esposo. Mas deseja muito mais.

Nem ela sabe o que sente. Filhos e esposo não desconfiam da languidez dos pensamentos. O companheiro não usa como ela os porões da alma.

Seu fascínio é arranhado pelas forças externas e por ela mesma, que não se desvenda.

Bárbara aclama São Jorge. Não há manifestação em que acredite mais, em que confie tanta profundeza e pele. As vizinhas foram se aproximando pelas respostas que nutriam alguma coisa, elas não sabiam o quê. Bárbara nunca soube de sua importância e assim foi melhor.

Acordou cedo, as pálpebras se abriram para o branco do teto, nem eram seis da manhã. Os ombros ajeitaram a cabeça dando a visão das samambaias que choravam do vaso ao chão. Levantou. Banhou o corpo com água quente. Passou um café forte acordando pelo cheiro a família. O chefe da casa saiu para o trabalho vestindo duas tonalidades de azul, cores que a empresa exigia de seus motoristas. Com cinco salários não era possível saciar os desejos de uma mulher e dois filhos.

Por isso, Bárbara vende bijuteria e lingerie para as vaidades. Rendas beges, correntes e pingentes de bonequinhos representando a prole. Sabia-se o sexo da ninhada pelo colar folheado a ouro. Bas-

8 Fuego, Andréa del. Minto enquanto posso. São Paulo: O nome da Rosa, 2004. 
tava uma delas usar algo diferente para que desencadeasse uma uniformização no bairro.

Unidas as mulheres. Quarentonas, dissolviam as tensões na calçada mesmo, debaixo do sol quente, conversando sobre violência, orixás e homens.

Desde a infância, Bárbara segue procissão pelo Santo Guerreiro. Caminha surda para os batimentos cardíacos do mundo. Caminha como sangue nas veias daquele que entrega a própria espada.

A chapa delgada e fria estanca a fome dos demônios.

O Guerreiro recebe glórias numa mesinha, baseada no corredor entre quarto e banheiro, é iluminada por grossas e brilhantes colunas de cera.

Bárbara bate os joelhos em frente ao altar todos os dias, o cavaleiro de gesso repousa num tecido urdido por suas mãos.

A fé é seu pilar central.

Não teme a morte do corpo, mas as necessárias para se encaixar na órbita dos elétrons, no eterno.

O filho mais velho sugeriu ao pai que levasse a mãe ao médico, assustado que estava com o olhar longo e fixo que Bárbara dirigia durante horas para o altar.

Não havia nada de estranho na família, aliás, uma família exemplar com as conveniências sociais. Nenhuma doença que entregasse alguém para a morte, nenhum acidente, nenhuma ruptura. Nada que justificasse tal isolamento intenso e estranho.

Algo faz retorcer seu corpo nas oito horas em que dorme, assim igual só o parto.

Quando não se lembra dos sonhos, amanhece preenchida de amor.

Quando se recorda, fica desperta, assombrada. Com medo do esposo, sente que o traiu deitada ao seu lado durante aquelas oito horas. Padece com a distância entre o sonho e o marido.

Olha para o companheiro e vê em si a mãe virgem e idolatrada, a culpa seca seus fluidos corporais. Mas só quando olha para ele. Por onde andará sua alma nas oito horas em que dorme o corpo? 
Rosvitha Friesen Blume. Traduzindo o erotismo místico do conto "Eucaristia",...

Plena ou assombrada isola-se naquele corredor estreito para orar sem se importar com a passagem de quem quer que seja.

Na noite deste dia em que o filho se preocupava com a mãe, Bárbara sonhou mais uma vez, passou seu corpo de sonho por entre as grades do inconsciente. Lá, nas temidas delícias, Bárbara vestiu um longo azul. O cabelo era de negro mistério e macio de veludo toque. Sentou-se na perfeita arquitetura, no banco de uma capela.

Sua respiração se ordenou em palavras cantadas. Pontos cantados. Orava hipnótica melodia.

As mãos espelhavam um lago, podia fertilizar com a pupila, irradiava. A capela a guardava da maldade não natural das coisas, daqueles que queriam entrar nem que fosse à machadada em seu paraíso.

Deslizando, saiu do templo para fazer as curvas do jardim. Mas um estrondo a interrompeu, na linha que destoa céu e terra, o dragão. A cauda réptil podia cortar até o nunca mais, sem chance de coagulação, de uma conciliação entre glóbulos brancos e vermelhos. Aproximou-se de Bárbara.

E então, homem e cavalo cruzaram o caminho do irascível. Vestindo metal, São Jorge dava a sua misericórdia. A lança afiada perfurou as asas do dragão, sem o domínio dos ares, o diabo desistiu de beber no cálice de Bárbara.

São Jorge seguia a brisa vinda dos cabelos dela, perfume. Estava embriagado pelo fermento das uvas de Salomão.

Abraçada pela emanação, ela sabia que era seguida. Não fazia idéia de que aquele homem romperia o resto dos seus himens, membranas que a botavam em cápsula. O leste soprou as mechas negras da devota, São Jorge contemplava vestido e cabelos ondulando como o mar.

Entraram e fecharam as portas da capela.

Abrigaram-se no santo ninho e materializaram a completa união. Quando se tocaram os corpos, nada foi capaz de estagnar as forças. Acenderam a fornalha para a mistura das divinas substâncias. 
Cadernos de Literatura em Tradução, n. 10, p. 9-22

\section{Das heilige Abendmahl}

Tradução de Claudia Hahn ${ }^{9}$

Barbara liebt ihren Mann. Aber sie begehrt viel mehr.

Nicht einmal sie selbst weiß, was sie fühlt. Ihre Söhne und ihr Mann ahnen nichts von Barbaras sinnlichen Gedanken. Ihr Partner kann nicht wie sie in die Tiefen der Seele eintauchen.

Ihre Welt bekommt erste Risse, woran die Umstände, aber auch sie selbst Schuld tragen, da sie sich niemandem anvertraut.

Barbara verehrt St. Georg. ${ }^{10}$ Es gibt nichts anderes, an das sie stärker glaubt, dem sie so mit Haut und Haaren verfallen ist. Die Nachbarinnen tuscheln untereinander über das, was vorgeht, auch wenn sie nicht wissen, was es ist. Barbara erfuhr nie etwas von ihrer Bedeutung und so war es auch besser.

Sie erwachte früh, den Blick auf das Weiß der Decke gerichtet. Es war noch nicht einmal sechs Uhr morgens. Die Schultern rückten den Kopf zurecht und gaben den Blick auf den Farn frei, der sich über die Vase auf den Fußboden ergoss. Sie stand auf, nahm ein heißes Bad und brühte einen starken Kaffee, von dessen Geruch der Rest der Familie aufgeweckt wurde. Der Hausherr machte sich auf den Weg zur Arbeit, in die blaue Uniform gekleidet, die das Unternehmen von seinen Fahrern erwartet. Mit dem bescheidenen Gehalt, das er dort verdiente, war es nicht möglich, die Wünsche einer Frau und zweier Kinder zu erfüllen.

9 Aluna do curso Tradução Literária ministrado por Rosvitha Blume na Universidade de Leipzig em 2006.

10 Laut Tradition ist Skt. Georg, im 3. Jahrh. in Kappadokien geboren und war ein Kämpfer und Märtyrer des Christentums. Er wurde von Kaiser Diokletian verfolgt und am 23.04.303, bis heute der Tag dieses Heiligen, geköpft. Nach einer bekannten Sage hätte er gegen einen Drachen gekämpft, der die Tochter eines Königs bedrohte. Deshalb gilt er bis heute als Retter der gefesselten Jungfrauen. Von der Katholischen Kirche wird er jedoch nicht offiziell als Heiliger anerkannt, zumal es keine historischen Quellen gibt, die seine Existenz belegen. 
Rosvitha Friesen Blume. Traduzindo o erotismo místico do conto "Eucaristia",...

Deshalb verkauft Barbara Schmuck und Dessous an die eitlen Damen. Beigefarbene Spitze, Halsketten und Anhänger mit kleinen Püppchen, die die Nachkommenschaft repräsentieren. An diesen vergoldeten Kettchen ließ sich das Geschlecht der Sprösslinge ablesen. Wenn auch nur eine Frau im Viertel mit etwas neuem ankam, taten es die anderen ihr unweigerlich nach.

Vereinte Frauen - alle mittleren Alters, lösten sie ihre Unstimmigkeiten gleich auf der Straße und schwatzten unter der heißen Sonne über Gewalt, Afro-Gottheiten und Männer.

Seit ihrer Kindheit nimmt Barbara an der Prozession des Heiligen Kriegers teil. Sie schreitet taub für den Herzschlag der Welt dahin. Sie bewegt sich wie das Blut in den Venen desjenigen, der das Schwert hingibt.

Die schmale und kalte Lanze stillt den Hunger der Dämonen.

Der Krieger erhält seine Verehrung auf einem Tischchen, das im Flur zwischen Schlafzimmer und Bad platziert ist und durch dicke glänzende Wachslichter erhellt wird.

Jeden Tag kniet Barbara vor dem Altar, die Ritterfigur aus Gips ruht dabei auf dem Geflecht ihrer Hände.

Der Glaube ist ihr Grundpfeiler.

Sie fürchtet sich nicht vor dem Tod des Körpers, jedoch vor denjenigen, die notwendig sind, um sich in die Umlaufbahn der Elektronen, in die Ewigkeit, einzufügen.

Ihr ältester Sohn bat seinen Vater, sie zum Arzt zu bringen, so erschrocken war er über den langen und starren Blick, den Barbara für Stunden auf den Altar fixiert hielt.

Es war nichts Außergewöhnliches an der Familie, sie war ein Musterbeispiel an sozialem Anstand. Es gab keine tödlichen Krankheiten, keine Unfälle, keine Zerwürfnisse. Nichts, was solch eine starke und merkwürdige Abkapselung gerechtfertigt hätte.

Während der acht Stunden Schlaf krümmt sich ihr Körper, als läge sie in den Wehen.

Wenn sie sich nicht an ihre Träume erinnert, erwacht sie am Morgen erfüllt von Liebe. 
Wenn sie sich jedoch erinnert, ist sie hellwach und verstört. Sie fürchtet sich vor ihrem Ehemann, denn sie fühlt, dass sie ihn in den acht Stunden, die sie neben ihm lag, betrogen hat. Sie leidet unter der Entfernung zwischen Traum und Ehemann.

Sie sieht ihren Partner an und sieht sich selbst als die jungfräuliche Mutter und abgöttisch geliebt und die Schuld trocknet ihre Körperflüssigkeiten. Jedoch nur, wenn sie ihn anschaut. Wohin entschwebt ihre Seele in den acht Stunden, in denen ihr Körper schläft?

Völlig erfüllt von Liebe oder verstört isoliert sie sich selbst auf dem schmalen Flur um zu beten, ohne sich darum zu kümmern, wer an ihr vorbeigeht.

In der Nacht des Tages, an dem sich der Sohn Sorgen um die Mutter gemacht hatte, träumte Barbara wieder einmal und entschwebte im Traum durch die Gitter des Unbewussten. Dort, in den gefürchteten Wonnen, trug Barbara ein langes blaues Kleid. Ihr Haar war von geheimnisvollem Schwarz und geschmeidig wie Samt in der Berührung. Sie setzte sich in die vollkommene Architektur, auf die Bank einer Kapelle.

Aus ihrer Atmung entstanden gesungene Worte. Gesungene Punkte. Sie betete eine hypnotische Melodie.

Ihre Hände spiegelten einen See wieder, sie konnte mit den Pupillen befruchten, ausstrahlen. Die Kapelle beschützte sie vor der unnatürlichen Bösartigkeit, vor denjenigen, die gewaltsam in ihr Paradies eindringen wollten.

Sie glitt von der Bank und verließ den Tempel, um im Garten lustzuwandeln. Aber ein Dröhnen unterbrach sie darin, ein Misston, der Himmel und Erde aus dem Gleichgewicht brachte - der Drachen.

Der Schwanz des Drachen konnte das Fleisch durchtrennen, bis das ewige Nichts erreicht war, ohne dass das Blut vorher gerann oder dass die weißen und roten Blutkörperchen einen Ausgleich herbeiführen konnten. Er näherte sich Barbara.

Plötzlich kreuzten Mann und Pferd den Weg des reizbaren Wesens. St. Georg, ganz in Metall gewandet, gab ihm den Gnadenstoß. Die scharfe Lanze durchdrang die Flügel des Drachens 
Rosvitha Friesen Blume. Traduzindo o erotismo místico do conto "Eucaristia",...

und ohne die Luft als Vorteil nutzen zu können, gab der Unhold es auf, vom Kelch Barbaras zu trinken.

St. Georg folgte der Brise Parfum, die von ihren Haaren ausging. Er war berauscht vom Keim der Trauben Salomos.

Umschlungen von seiner Aura, fühlte sie, dass er ihr folgte. Noch wusste sie nicht, dass dieser Mann den Rest ihrer Unschuld zerreißen würde, eine Membran, die sie in einer Kapsel schützte. Der Ostwind wehte durch die schwarze Haarpracht der Devoten. St. Georg betrachtete ihr Kleid und die Haare, die sich wie das Meer wellten.

Sie traten in die Kapelle und schlossen die Türen hinter sich.

An diesem heiligen Ort suchten sie Zuflucht und verschmolzen zu einem Ganzen. Als sich ihre Körper berührten, konnte nichts diese Kräfte stoppen. Sie schürten das Feuer für die Mischung göttlicher Substanzen. 